\title{
Pharmacokinetic characteristics and microbiologic appropriateness of cefazolin for perioperative antibiotic prophylaxis in elective cardiac surgery
}

\author{
Christian Lanckohr, MD, ${ }^{a}$ Dagmar Horn, ${ }^{b}$ Swantje Voeller, PhD, ${ }^{c}$ Georg Hempel, PhD, ${ }^{c}$ \\ Manfred Fobker, PhD, ${ }^{\mathrm{d}}$ Henryk Welp, MD,${ }^{\mathrm{e}}$ Robin Koeck, MD ${ }^{\mathrm{f}}$ and Bjoern Ellger, MD
}

\begin{abstract}
Objective: Adequate levels of perioperative antibiotic prophylaxis are essential for prevention of surgical site infections. We examined pharmacokinetic details of $2 \mathrm{~g}$ cefazolin administered during induction of anesthesia with repeat dosing shortly after initiation of cardiopulmonary bypass (CPB) in cardiac surgery.

Methods: To identify the microbiologic flora targeted with prophylaxis, pre-, and postoperative swabs were taken from sternal skin. Blood samples for measurement of cefazolin were obtained in 24 patients. Drug levels were used for population pharmacokinetic modeling using Nonmem software (Icon Development Solutions, San Antonio, Tex).
\end{abstract}

Results: More than $90 \%$ of bacteria on sternal skin were sensitive to cefazolin, indicating minimal inhibitory concentrations $<8 \mathrm{mg} / \mathrm{L}$. All serum levels of cefazolin were above $8 \mathrm{mg} / \mathrm{L}$ and might thus effectively prevent infection. Pharmacokinetic modeling in a 1-compartment model predicted a population mean clearance $(\mathrm{CL})$ of $5.23 \mathrm{~L} / \mathrm{h}$ and a volume of distribution $\left(\mathrm{V}_{\mathrm{d}}\right)$ of $15.8 \mathrm{~L}$. CPB increased $\mathrm{V}_{\mathrm{d}}$ from $14.4 \mathrm{~L}$ to $22.1 \mathrm{~L}$ with a consecutive reduction to $18 \mathrm{~L}$ after the end of extracorporeal circulation. The final model implemented interindividual variability on $C L$ and $V_{d}$, incorporating the covariates $C P B$ and albumin on $\mathrm{V}_{\mathrm{d}}$ and creatinine clearance on CL. Goodness-of-fit calculations showed that this model adequately describes the data derived from our clinical cohort.

Conclusions: Two grams of cefazolin at induction of anesthesia with a repeat dose after initiation of CPB ensures adequate drug levels to target a majority of pathogens of surgical site infections. Pharmacokinetic modeling demonstrated a significant influence of CPB on the volume of distribution and elimination of cefazolin. Other influences on pharmacokinetic parameters were albumin, protein, and creatinine clearance. (J Thorac Cardiovasc Surg 2016;152:603-10)

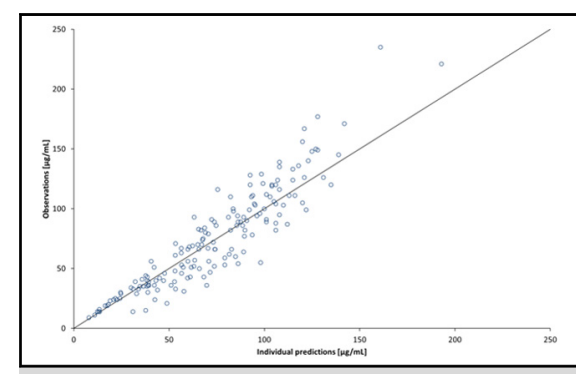

Performance of a pharmacokinetic model in predicting cefazolin levels.

Central Message

A pharmacokinetic prediction of cefazolin levels is possible. An early repetition dose of $2 \mathrm{~g}$ cefazolin on cardiopulmonary bypass is warranted.

\section{Perspective}

Factors influencing the pharmacokinetic parameters of cefazolin in cardiac surgery are identified, allowing for the prediction of blood levels. The early repetition of $2 \mathrm{~g}$ cefazolin shortly after start of cardiopulmonary bypass seems warranted. An improved understanding of cefazolin pharmacokinetic characteristics helps optimize its use for the prevention of surgical site infection.

See Editorial Commentary page 611

\footnotetext{
From the Departments of anesthesiology, Intensive Care Medicine and Pain Therapy, ${ }^{\mathrm{b}}$ Pharmacy, ${ }^{\mathrm{d}}$ Laboratory Medicine, and ${ }^{\mathrm{e}}$ Cardiac Surgery, and ${ }^{\mathrm{f}}$ Institute of Medical Microbiology, University of Muenster; and ${ }^{\mathrm{c}}$ Department of Pharmaceutical and Medical Chemistry - Clinical Pharmacy, Westfaelische Wilhelm-University Muenster, Muenster, Germany.

This work was supported by the Department of Anesthesiology, Intensive Care Medicine, and Pain Therapy at the University Hospital Muenster

C.L. and D.M. contributed equally to this article.

Received for publication Sept 24, 2015; revisions received March 7, 2016; accepted for publication April 2, 2016; available ahead of print May 18, 2016.

Address for reprints: Christian Lanckohr, MD, Department of Anesthesiology, Intensive Care Medicine and Pain Therapy University Hospital Muenster, AlbertSchweitzer-Campus 1, Building A1 D-48149, Muenster, Germany (E-mail: lanckohr@anit.uni-muenster.de).

$0022-5223 / \$ 36.00$

Copyright (c) 2016 by The American Association for Thoracic Surgery

http://dx.doi.org/10.1016/j.jtcvs.2016.04.024
}

Deep sternal wound infection in cardiac surgery is a serious postoperative complication with an incidence of approximately $1.8 \%{ }^{1,2}$ Prevention strategies are multifactorial. ${ }^{3,4}$ The administration of a perioperative antibiotic prophylaxis (PAP) is a cornerstone in the prevention of surgical site

Scanning this $\mathrm{QR}$ code will take you to the article title page.

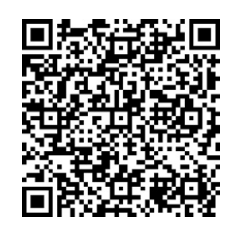




$$
\begin{aligned}
& \text { Abbreviations and Acronyms } \\
& \text { CL }=\text { clearance } \\
& \text { CPB }=\text { cardiopulmonary bypass } \\
& \text { PAP }=\text { perioperative antibiotic prophylaxis } \\
& \text { SSI }=\text { surgical site infection } \\
& \text { STS }=\text { Society of Thoracic Surgeons } \\
& \mathrm{V}_{\mathrm{d}}=\text { volume of distribution }
\end{aligned}
$$

infections (SSI) and many studies have demonstrated the relevance of PAP in cardiac surgery. Current guidelines by the Society of Thoracic Surgeons (STS) provide recommendations concerning its clinical application.,

The first-generation cephalosporin cefazolin is widely used for PAP in cardiac surgery in areas with low prevalence of methicillin-resistant Staphylococcus aureus. The STS guidelines recommend an initial dose of $2 \mathrm{~g}$ cefazolin in patients weighing more than $60 \mathrm{~kg}$, with repetition doses of $1 \mathrm{~g}$ every 3 to 4 hours if the procedure continues. Furthermore, a delay of a repetition dose until after discontinuation of cardiopulmonary bypass $(\mathrm{CPB})$ is recommended if this is achieved within 3 to 4 hours after the initial dose. Despite uncertainty regarding the timing and dose of follow-up applications, the benefit of additional intraoperative doses of cefazolin in preventing SSI in heart surgery is well established. ${ }^{7,8}$ The feasibility of a continuous infusion of cefazolin has been reported, ${ }^{9,10}$ but these dosing schemes are not standard of care at the time of this investigation.

A number of publications report serum levels of cefazolin achieved with various dosing regimens in cardiac surgery patients. ${ }^{10-17}$ Besides drug levels, little information is available with regard to factors influencing the pharmacokinetic parameters of cefazolin. An issue of uncertainty is the definition of adequacy of cefazolin levels. A number of studies have attempted to correlate cefazolin levels in plasma with the minimal inhibitory concentration of the most likely pathogens. Antibiotic levels above the minimal inhibitory concentration in plasma are usually considered sufficient. The associated tissue levels of cefazolin are difficult to determine and few publications report antibiotic concentrations in tissue or interstitial fluid. .,10,18,19 $^{2}$

The perioperative prophylaxis scheme at University Hospital Muenster differs from the recommendations of the STS. It consists of $2 \mathrm{~g}$ cefazolin administered during induction of anesthesia, followed by $2 \mathrm{~g}$ cefazolin shortly after the start of CBP. Repetition doses are only given when operation time exceeds 4 hours after the second dose. This practice was introduced because pharmacologic studies demonstrated the influence of CPB on levels of prophylactic antibiotics and subtherapeutic drug levels should be prevented. ${ }^{12,14,17}$

We report serum levels achieved with this dosing scheme and determine factors influencing antibiotic levels using a population pharmacokinetic approach. To evaluate the spectrum of relevant pathogens and their sensitivity to cefazolin a concomitant microbial analysis was performed.

\section{METHODS \\ Patient Population}

This study was conducted prospectively in September 2012 at University Hospital Muenster. The study protocol was approved by the local ethics committee (Study Code 02-AnIT-12). Written informed consent was obtained from 24 adult, competent patients scheduled for routine cardiac surgery with use of CPB. Exclusion criteria were an allergy to cephalosporin medications precluding the use of cefazolin and chronic end-stage renal failure. Written informed consent was obtained from all patients on the day before surgery. Age, height, weight, and sex were recorded on the day before surgery. Laboratory measurements of creatinine, urea, albumin, and protein were performed on the day of surgery from blood samples drawn at incision and upon admission to the intensive care unit.

\section{Application of Cefazolin}

After induction of anesthesia, a dose of $2 \mathrm{~g}$ cefazolin (Fresenius Kabi, Bad Homburg, Germany) was administered intravenously over 10 to $15 \mathrm{mi}-$ nutes. Another $2 \mathrm{~g}$ cefazolin was given shortly after institution of CBP. Intraoperative repeat doses were only given if the procedure lasted longer than 4 hours after the second dose.

\section{Microbiologic Sampling}

Preoperative microbiologic samples from sternal skin were collected using rayon swabs (Transwab Amies, MWE Medical Wire, Corsham, United Kingdom) after induction of anesthesia before skin disinfection. Postoperative samples were collected immediately before final closure of sternal skin after removal of the operative foil and before skin preparation with iodine solution. After collection, swabs were immediately transported to the laboratory. Swabs were streaked onto Columbia blood agar and incubated aerobically for 24 hours at $36^{\circ} \mathrm{C}$. The species of all microorganisms detected was characterized using matrix assisted laser desorption ionization-time of flight mass spectrometry. Antimicrobial resistance testing was performed using agar disk diffusion tests (on Mueller-Hinton agar and, for fastidious bacteria, Mueller-Hinton supplemented with 5\% defibrinated horse blood and $20 \mathrm{mg} / \mathrm{L} \beta$-NAD (Oxoid, Wesel, Germany).

\section{Extracorporeal Circuit}

Priming volume for the extracorporeal circuit was $1500 \mathrm{~mL}$ in total (1250 mL balanced electrolyte solution, $250 \mathrm{~mL}$ mannitol, and $5.000 \mathrm{IU}$ heparin). If hemoglobin levels were below $10 \mathrm{mg} / \mathrm{dL}$ preoperatively, $500 \mathrm{~mL}$ packed red cells were added. For cardioplegia, Calafiore solution was used. Patients were not cooled below $32^{\circ} \mathrm{C}$. Flow during CBP was about $70 \mathrm{~mL} / \mathrm{m}^{2}$ of body surface area.

\section{Blood Sampling for Cefazolin Measurement}

Blood samples were drawn from the arterial line into ethylenediaminetetraacetic acid-containing tubes (S-Monovette $2.7 \mathrm{mLK} 3 \mathrm{E}$, Sarstedt, Nuembrecht, Germany) at incision, shortly before cannulation and institution of CPB, after institution of CPB before second dose cefazolin, shortly after complete infusion of cefazolin on CPB, after the end of CPB and removal of cannulas, on admission to the intensive care unit postoperatively, 4 hours after admission to the intensive care unit (Figure 1, $A$ ).

\section{Cefazolin Assay}

The whole blood concentration of cefazolin in human serum was analyzed with reversed-phase high-performance liquid chromatography on a 116 liquid chromatograph (Beckman Coulter GmbH, Krefeld, Germany) interfaced with a model 168 dioden array detector. Interassay and 


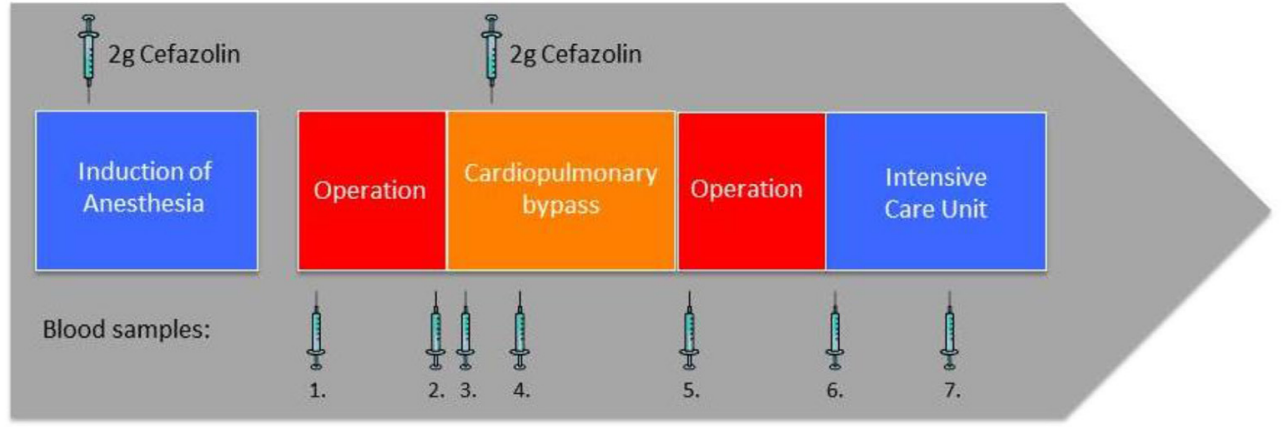

A

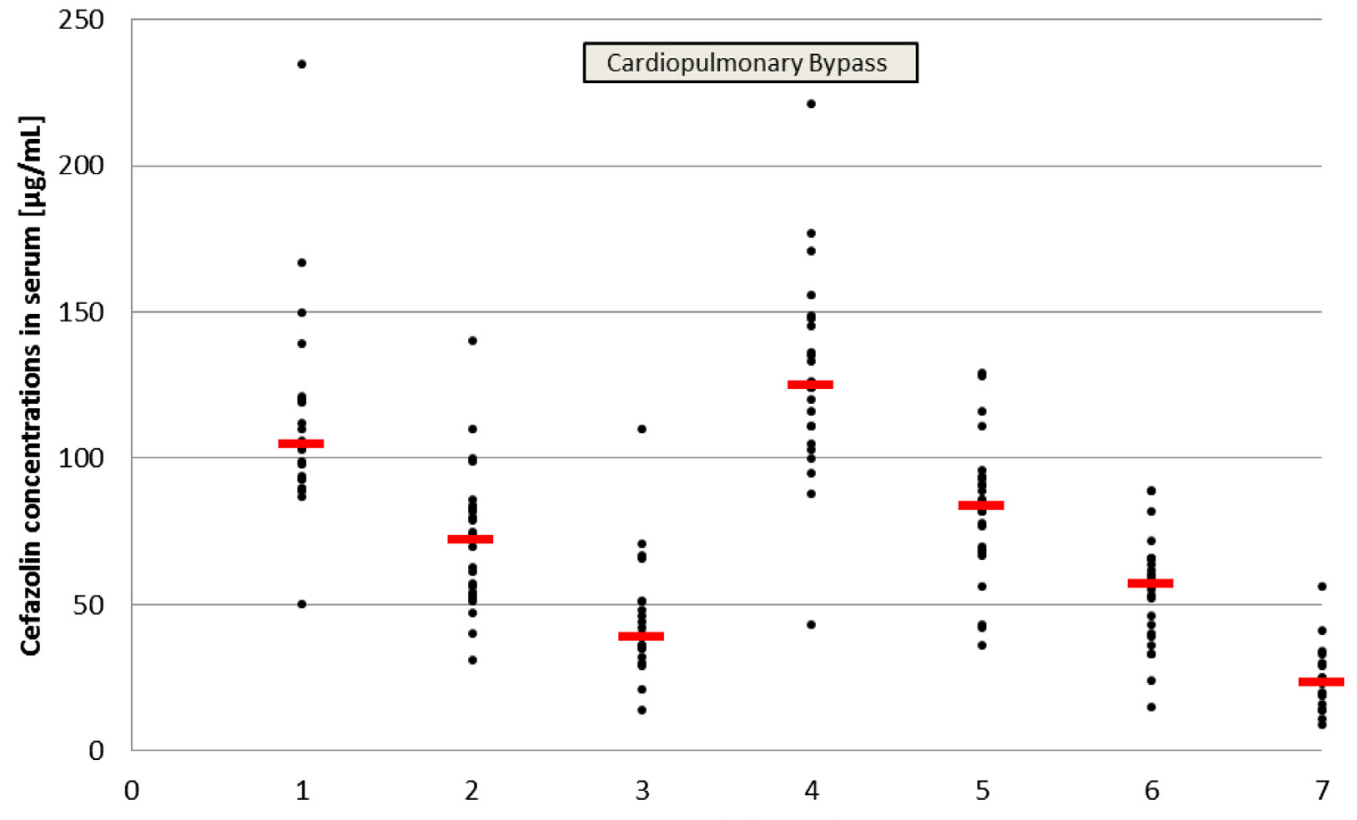

B

Blood samples at different time points

FIGURE 1. A, Administration of cefazolin and blood sampling during the perioperative period. Cefazolin was administered during the induction of anesthesia and shortly after the institution of cardiopulmonary bypass. Blood samples were taken at 7 time points. B, Serum concentrations of cefazolin obtained at different time points. Red bars denote median values. Intervals between sampling points on the x-axis are not uniform. The period of cardiopulmonary bypass is marked.

intra-assay coefficients of variation were $5.2 \%$ and $3.5 \%$, respectively. Linearity was observed in the concentration range of 1 to $500 \mathrm{mg} / \mathrm{L}$ $\left(r^{2}=0.9994\right)$. The lower limit of detection and limit of quantification were 0.1 and $0.3 \mathrm{mg} / \mathrm{L}$, respectively.

\section{Pharmacokinetic Analyses}

A population pharmacokinetic analysis was performed using the software Nonmem version 7.2 (Icon Development Solutions, San Antonio, Tex). The program was used in mixed model mode to account for random effects of multiple measurements per patient. Interindividual as well as random variability were assessed separately. Interindividual variability is defined as the variability from 1 subject to another as opposed to intraindividual variability, which is the variability from 1 dose to another in 1 subject. Intraindividual variability was not assessed in this analysis.

Model development proceeded in a stepwise manner. First the most adequate compartment model was determined, next the most suitable residual error model was selected and interindividual variability was implemented on all possible parameters, allowing these parameters to vary from patient to patient. After completion of the base model a covariate analysis was performed to identify possible patient-specific factors that might influence the pharmacokinetic parameters of cefazolin. The following covariates were tested: $\mathrm{CPB}$, age, height, weight, sex, creatinine, urea, creatinine clearance, albumin, protein, and bilirubin. To handle $\mathrm{CPB}$ as a time-varying covariate, at the time of initiation of $\mathrm{CPB}$ the covariate was changed from 0 to 1 , and changed back from 1 to 0 when CPB ended. The first order conditional estimation method with interaction was used throughout model development. Model evaluation was carried out using several goodness-of-fit plots.

The inclusion of each available covariate on clearance $(\mathrm{CL})$ and volume of distribution $\left(\mathrm{V}_{\mathrm{d}}\right)$ showed that $\mathrm{CPB}$ on either $\mathrm{CL}$ or $\mathrm{V}_{\mathrm{d}}$, albumin or protein on $\mathrm{V}_{\mathrm{d}}$ and creatinine clearance on $\mathrm{CL}$ led to an improvement of the model. The inclusion of albumin on $\mathrm{V}_{\mathrm{d}}$ resulted in the most significant improvement of the model, followed by protein on $\mathrm{V}_{\mathrm{d}}, \mathrm{CPB}$ on $\mathrm{V}_{\mathrm{d}}, \mathrm{CPB}$ on CL, and creatinine clearance on CL (all $P$ values $>.001$ ). Patient weight was not found to have a significant influence on $\mathrm{V}_{\mathrm{d}}$. After testing for the influence of each single parameter, combinations of those parameters were 
tested. An inclusion of $\mathrm{CPB}$ on $\mathrm{CL}$ and $\mathrm{V}_{\mathrm{d}}$ did not lead to an improved fit. Therefore, $\mathrm{CPB}$ was included on $\mathrm{V}_{\mathrm{d}}$ only. Similarly, the combined inclusion of protein and albumin on $\mathrm{V}_{\mathrm{d}}$ did not lead to an improved fit, because these 2 parameters might be highly correlated. However, the additional inclusion of albumin into the model with CPB improved the prediction of the model. This model could further then be improved by the inclusion of creatinine clearance on CL. The final model was a 1-compartment model with interindividual variability on $\mathrm{CL}$ and $\mathrm{V}_{\mathrm{d}}$, incorporating the covariates $\mathrm{CPB}$ and albumin on $\mathrm{V}_{\mathrm{d}}$ and creatinine clearance on CL. Although 2-compartment models for cefazolin are reported in literature ${ }^{20}$ a 1-compartment model was used in this analysis because the data were not sufficient to adequately describe the second compartment.

\section{RESULTS}

Patient characteristics, details of the surgical procedures, and various laboratory values are reported in Table 1. Preoperative cefazolin was administered at a median of $51.5 \mathrm{mi}-$ nutes before incision, after a median of 130.5 minutes the second dose was given. No patient received a third dose.

Results of microbiologic diagnostics are shown in Table 2. In this patient cohort 51 of $56(91 \%)$ isolates detected at the sternal skin before surgery and 23 of 25 $(92 \%)$ of those found before wound closure were susceptible to cefazolin when tested with an agar disc diffusion method. This indicates that the minimal inhibitory concentrations for these bacteria were below $8 \mathrm{mg} / \mathrm{L}$.

Serum concentrations of cefazolin at different points in time are shown in Figure 1, $B$. All samples obtained had cefazolin levels above $8 \mathrm{mg} / \mathrm{L}$, even 4 hours after admission to an intensive care unit (time point 7). This dosing scheme for cefazolin can therefore be considered adequate for $>90 \%$ of bacterial isolates detected from skin swabs before and at the end of surgery.

In our cohort of patients, a single instance of sternal SSI with the necessity of surgical revision occurred. No singlesite infections occurred at the locations of saphenous graft harvesting.

\section{Pharmacokinetic Analysis}

The precision of the estimated parameters $\left(\mathrm{V}_{\mathrm{d}}\right.$ and $\left.\mathrm{CL}\right)$ was high with a standard error of $<20 \%$ (Table 3). The final model predicted a population mean clearance of $5.23 \mathrm{~L} / \mathrm{h}$ and a volume of distribution of $15.8 \mathrm{~L}$. Figure 2 displays the observed concentrations versus individual and population predictions of the final model. The goodness-of-fit plots demonstrate that our pharmacokinetic model can adequately describe the data derived from the clinical cohort.

There was a statistically significant effect of the initiation of CPB and albumin (both with $P<.001$ ) on the individual model predictions for the volume of distribution of cefazolin (Figure 3). CPB increased the $\mathrm{V}_{\mathrm{d}}$ from $14.4 \mathrm{~L}$ to $22.1 \mathrm{~L}$ with a consecutive reduction to $18 \mathrm{~L}$ after the end of extracorporeal circulation. Furthermore, creatinine clearance had a statistically significant effect on the clearance of cefazolin $(P<.01)$.
TABLE 1. Patient characteristics, pre- and postoperative laboratory values, and procedural data

\begin{tabular}{|c|c|}
\hline Patient characteristic & Result \\
\hline \multicolumn{2}{|l|}{ Sex } \\
\hline Male & 16 \\
\hline Female & 8 \\
\hline Age, y & $68(40-85)$ \\
\hline Weight, kg & $81(48-116)$ \\
\hline Body mass index & $27(21-33)$ \\
\hline Diabetes mellitus & $7 / 24(29 \%)$ \\
\hline Current smoker & $6 / 24(25 \%)$ \\
\hline \multicolumn{2}{|l|}{ Creatinine, $\mathrm{mg} / \mathrm{dL}$} \\
\hline Preoperatively & $1.1(0.6-1.9)$ \\
\hline Postoperatively & $1.0(0.6-1.9)$ \\
\hline \multicolumn{2}{|l|}{ Creatinine clearance, $\mathrm{mL} / \mathrm{min}$} \\
\hline Preoperatively & $76(37-125)$ \\
\hline Postoperatively & $83(37-133)$ \\
\hline \multicolumn{2}{|l|}{ Urea, $\mathrm{mg} / \mathrm{dL}$} \\
\hline Preoperatively & $19.5(10-39)$ \\
\hline Postoperatively & $18(10-39)$ \\
\hline \multicolumn{2}{|l|}{ Albumin, g/dL } \\
\hline Preoperatively & $3.45(2.8-4.1)$ \\
\hline Postoperatively & $2.6(1.5-3.6)$ \\
\hline \multicolumn{2}{|l|}{ Protein, g/dL } \\
\hline Preoperatively & $6.05(4.4-7.4)$ \\
\hline Postoperatively & $4.4(2.7-5.7)$ \\
\hline $\begin{array}{l}\text { European System for Cardiac Operative Risk } \\
\text { Evaluation score }\end{array}$ & $4.06(0.88-57.01)$ \\
\hline \multicolumn{2}{|l|}{ Type of surgery } \\
\hline CABG & 14 \\
\hline Valve replacement & 3 \\
\hline Combination $(\mathrm{CABG}+$ valve $)$ & 5 \\
\hline Other & 2 \\
\hline Duration of surgery, min & $261(175-341)$ \\
\hline Duration of cardiopulmonary bypass, min & $122(43-176)$ \\
\hline Duration of crossclamping, min & $82(0-130)$ \\
\hline Time from first dose of cefazolin to incision, $\min$ & $51.5(35-112)$ \\
\hline Time from first dose of cefazolin to second dose, min & $130.5(73-200)$ \\
\hline $\begin{array}{l}\text { Time from second dose of cefazolin to ICU } \\
\text { admission, } \min \end{array}$ & $214.5(110-405)$ \\
\hline
\end{tabular}

\section{DISCUSSION}

In this study, we examined pharmacokinetic characteristics of $2 \mathrm{~g}$ cefazolin at induction of anesthesia with a repetition dose of $2 \mathrm{~g}$ shortly after institution of CPB in patients undergoing elective cardiac surgery. This practice differs from the current recommendations of the STS, because it doubles the repetition dose and prepones its administration to the beginning of CPB. Plasma levels obtained with this dosing scheme are inhibitory for $>90 \%$ of bacteria found in pre- and postoperative skin swabs in our cohort. Pharmacokinetic calculations in a 1-compartment model identified an influence of creatinine clearance, albumin levels, and $\mathrm{CPB}$ on drug levels. Body weight had no influence on levels 
TABLE 2. Results of microbiologic sampling of sternal skin preoperatively (before disinfection) and postoperatively (before final wound closure). In total, 56 distinct isolates were recovered from preoperative swabs, in comparison to 25 isolates from postoperative swabs. Shown here are the absolute numbers of different bacteria species and their relative percentage with regard to all isolates. Also shown are the percentages of isolates with susceptibility to cefazolin

\begin{tabular}{|c|c|c|c|c|c|c|c|c|}
\hline Sample & CoNS & $\begin{array}{c}\text { Staaphylococcus } \\
\text { aureus }\end{array}$ & $\begin{array}{c}\text { Viridans } \\
\text { streptococci } \\
\end{array}$ & Bacillus sp & Micrococci & Coryne-bacteria & Rothia sp & $\begin{array}{l}\text { Acineto- } \\
\text { bacter sp. }\end{array}$ \\
\hline Preoperative & $45 / 56(80.4 \%)$ & $1 / 56(1.8 \%)$ & $2 / 56(3.6 \%)$ & $2 / 56(3.6 \%)$ & $2 / 56(3.6 \%)$ & $2 / 56(3.6 \%)$ & $1 / 56(1.8 \%)$ & $1 / 56(1.8 \%)$ \\
\hline Cefazolin susceptibility* & $41 / 45(91 \%)$ & $1 / 1(100 \%)$ & $2 / 2(100 \%)$ & $2 / 2(100 \%)$ & $2 / 2(100 \%)$ & $2 / 2(100 \%)$ & $1 / 1(100 \%)$ & $0 / 1(0 \%)$ \\
\hline Postoperative & $25 / 25(100 \%)$ & 0 & 0 & 0 & 0 & 0 & 0 & 0 \\
\hline Cefazolin Susceptibility* & $23 / 25(92 \%)$ & & & & & & & \\
\hline
\end{tabular}

Values are presented as n/N (\%). CoNS, Coagulase-negative Staphylococcus. *Susceptibility to cefazolin (as determined by testing indicator antibiotics (ie, cefoxitin for staphylococci and micrococci; penicillin $\mathrm{G}$ for streptococci, corynebacteria, Bacillus sp, and Rothia sp). Acinetobacter sp was regarded intrinsically resistant to cefazolin.

of cefazolin in our cohort. The model developed here allows for prospective predictions of cefazolin concentrations in a bedside setting in individual patients.

The administration of $1 \mathrm{~g}$ cefazolin at induction and $1 \mathrm{~g}$ before wound closure was examined by Cafarelli and colleagues, ${ }^{15}$ showing insufficient drug levels in longer operations. A similar result was reached by Fellinger and colleagues $^{13}$ who reported perioperative serum levels of $1 \mathrm{~g}$ cefazolin at induction of anesthesia and immediately after the institution of CPB. They observed considerable fluctuations of drug levels and suggested to test doses of $2 \mathrm{~g}$ cefazolin to ascertain effective levels of cefazolin during the operation. Our results corroborate this suggestion, which has not been examined so far. The dosing scheme reported here accomplished plasma levels of cefazolin above $8 \mathrm{mg} / \mathrm{L}$ in all patients up to 4 hours after intensive care unit admission. The adequacy of this prophylactic regime is supported by microbiologic results obtained from pre- and postoperative skin sampling.

The initiation of CPB caused a considerable and rapid drop in cefazolin levels in our patients. In a short period of time between sampling points 2 and 3 (median span of 10 minutes [range, 4-30 minutes]), drug concentration dropped significantly. This finding resembles previously published results. ${ }^{12,14,17}$ In pharmacokinetic terms, this drop reflects an increase in the volume of distribution of cefazolin. The early administration of a repetition dose shortly after the start of extracorporeal circulation counteracted this rapid drop of cefazolin concentrations. A further decrease to

TABLE 3. Results of pharmacokinetic modeling

\begin{tabular}{lcc}
\hline \multicolumn{1}{c}{ Parameter } & $\begin{array}{c}\text { Population mean } \\
\text { (residual } \\
\text { standard error) }\end{array}$ & $\begin{array}{c}\text { Interindividual } \\
\text { variability (residual } \\
\text { standard error) }\end{array}$ \\
\hline Clearance, $\mathrm{L} / \mathrm{h}$ & $5.23(3.2 \%)$ & $10.1(24.5 \%)$ \\
Volume of distribution, $\mathrm{L}$ & $15.8(4.9 \%)$ & $17.5(37.8 \%)$ \\
Propensity error & $23.2(7.1 \%)$ & - \\
Influence of CPB on $\mathrm{V}_{\mathrm{d}}$ & $-0.0849(82 \%)$ & - \\
Influence of albumin on $\mathrm{V}_{\mathrm{d}}$ & $-0.178(18.2 \%)$ & - \\
Influence of creatinine & $0.00532(17.3 \%)$ & - \\
$\quad$ clearance on CL & & \\
\hline$C P B$, Cardiopulmonary bypass; $V_{d}$, volume of distribution; $C L$, clearance.
\end{tabular}

subtherapeutic antibiotic levels appears likely if the second dose is postponed or omitted. Because trends in drug levels are difficult to predict in individual patients, our more aggressive practice is a reasonable choice to optimize dosing efficiency in the absence of rapidly available drug levels. The approach appears safe, because adverse effects of temporarily high cefazolin levels are unlikely and rather theoretical. Indeed, high initial doses of cefazolin $(4 \mathrm{~g}$ before surgery) have been used and reported without obvious adverse effects. ${ }^{18,19,21}$ Furthermore, the cost of cefazolin is rather low and the economic burden of a second dose appears negligible. With regard to collateral damages of antibiotic exposure, the induction of Clostridium difficile infection must be recognized, but seems to be more a problem of extended prophylaxis schemes. $^{22}$

From a more practical point of view, the temporal association of cefazolin redosing to the start of CPB might be a step to ensure that the second dose of antibiotic is in fact given. The risk of simply forgetting the repetition dose is quite real and a number of studies demonstrate that alert systems have the potential to improve compliance with redosing. ${ }^{23,24}$ The start of CPB is an important step during cardiac surgery, which is invariably noticed by all persons involved (ie, surgeon, anesthesiologist, perfusionist, and nurses). A coupling of antibiotic administration to this event is therefore advantageous for both pharmacokinetic and practical reasons.

Our analysis identifies factors influencing the perioperative kinetics of cefazolin in cardiac surgery with use of CPB. Only few studies so far have performed pharmacokinetic calculations in this setting, ${ }^{11,16,18,19}$ typically mere drug levels are reported without further insight into details. ${ }^{9,10,12,13,15,17,21}$ We are not aware of population pharmacokinetic studies of cefazolin in cardiac surgery, attempting to identify influential factors for the building of a predictive model.

We found kidney function to be a relevant factor influencing cefazolin clearance. This association is plausible because cefazolin is excreted renally. Our results thus differ from the observations of Kosaka and colleagues, ${ }^{16}$ who reported a lack of correlation of kidney function and cefazolin levels above a creatinine clearance of $50 \mathrm{~mL} / \mathrm{min}$. The 


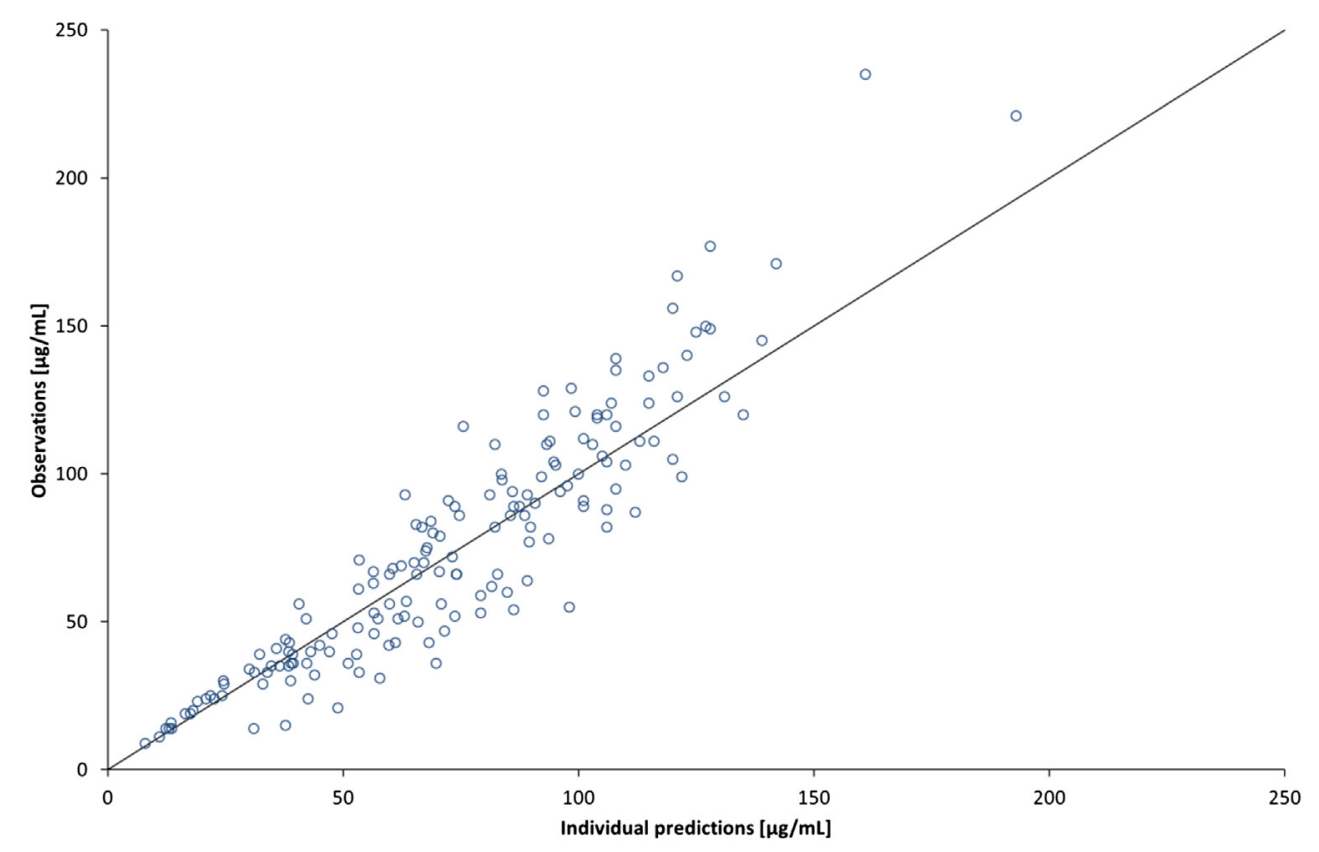

A

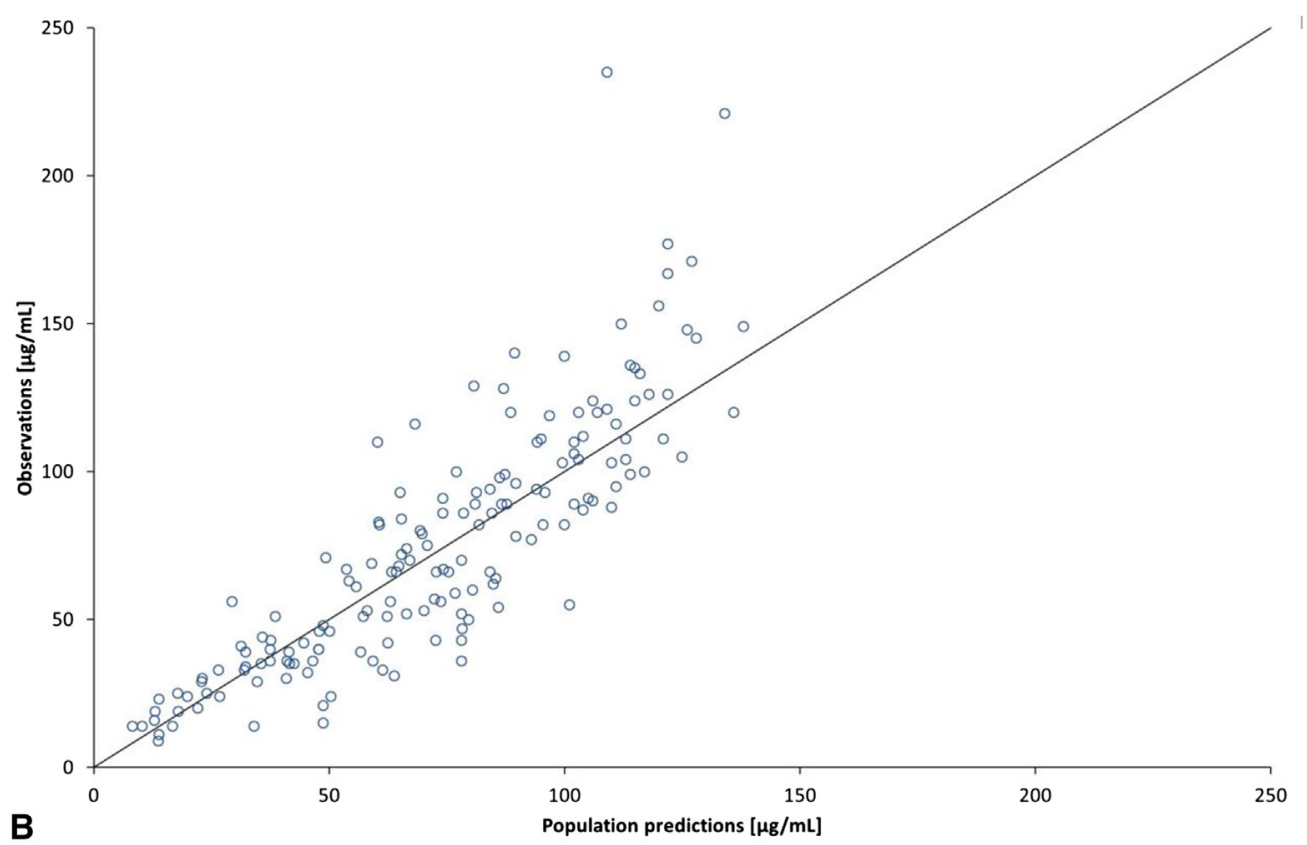

FIGURE 2. Performance of a 1-compartment pharmacokinetic model. Each circle represents a cefazolin concentration. The $y$-axis denotes the observed (ie, measured) drug levels, the $x$-axis reflects the predicted (ie, calculated) levels. A, Observed versus individually predicted drug levels. B, Observed versus population predictions.

majority of our patients had a creatinine clearance above $50 \mathrm{~mL} / \mathrm{min}$ and the correlation is strong. Still, we cannot exclude an even more pronounced influence of kidney function at clearances lower than $50 \mathrm{~mL} / \mathrm{min}$ because we lack sufficient numbers of patients in this category. A decreased excretion of cefazolin due to reduced kidney function would theoretically lead to a protracted fall in serum levels, possibly extending the period of sufficient antibiotic coverage. Whether reduced kidney function might allow for less aggressive dosing remains unclear. There is no doubt that the risks of overdosing seem smaller than adverse effects caused by underdosing. 


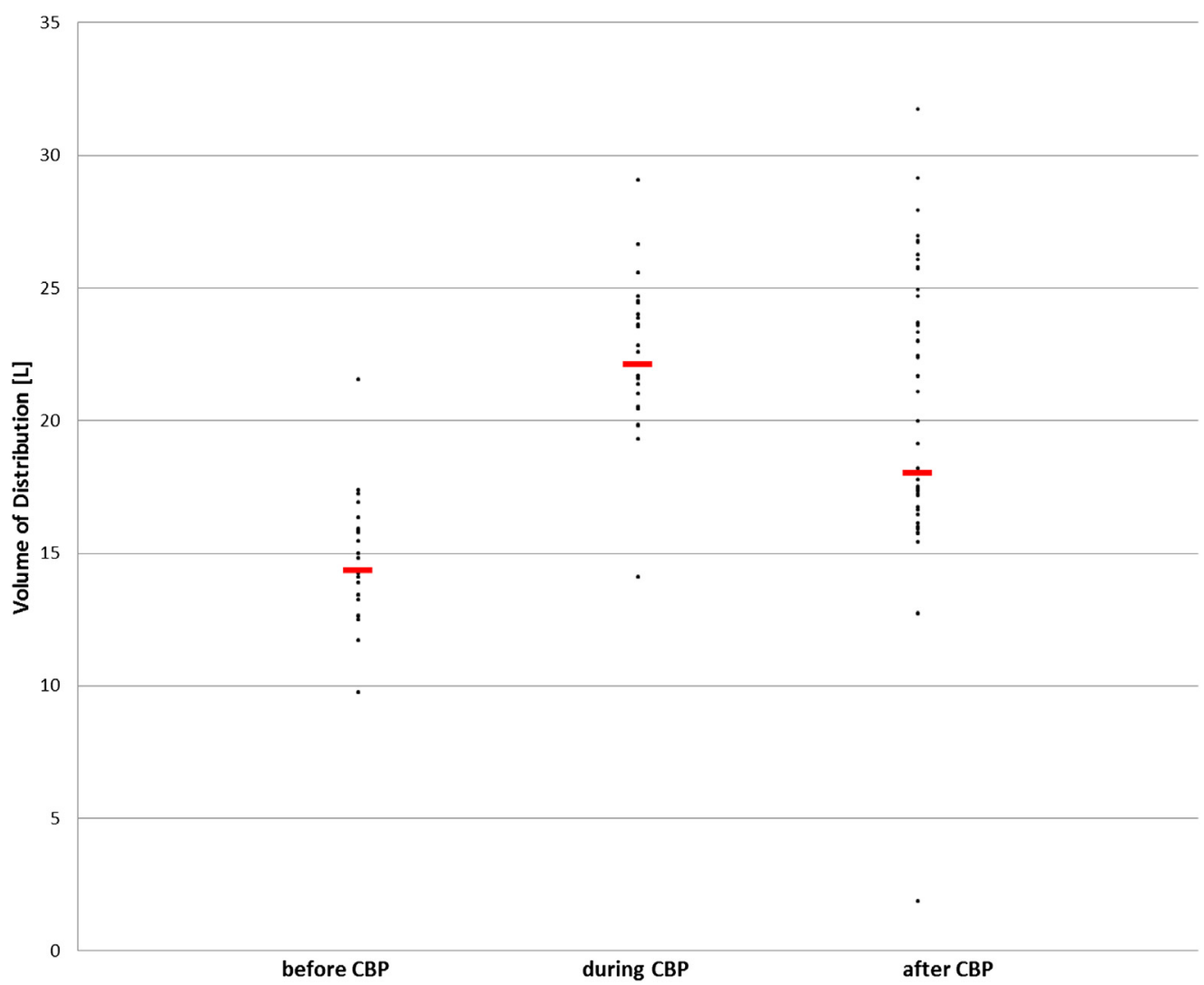

FIGURE 3. Volumes of distribution of cefazolin calculated on the basis of measured cefazolin levels. Each dot represents an individual patient, the red bar denotes the median values. The volumes of distribution are shown for the periods before, during and after cardiopulmonary bypass $(C P B)$.

The institution of CPB temporarily increases the volume of distribution, thus prolonging the half-life of cefazolin. These changes are reversed after the end of extracorporeal circulation, although the exact preoperative levels were not reached in the period we studied. An interesting and new observation is the influence of both albumin and protein levels on serum concentrations of cefazolin. Levels of albumin and protein decreased significantly over the course of the operation (Table 1), causing a reduction in the volume of distribution of cefazolin. To our knowledge, this pharmacokinetic influence has not been reported. The exact mechanism of this alteration is unclear. A possible mechanism might be the adsorption of plasma proteins and albumin (or cefazolin) to the inner surfaces of the extracorporeal circuit. ${ }^{25}$ Because cefazolin is $80 \%$ bound to albumin, a gross reduction of albumin and other blood proteins would lead to a relatively rapid net loss of cefazolin into the extracorporeal circuit.

There are a number of limitations to our study. We included patients scheduled for elective and rather standardized procedures. Still, we believe that our results allow for conclusions applicable to a majority of cardiac surgical procedures. Furthermore, we did not include children or patients receiving chronic dialysis. Our results cannot be extrapolated to these groups of patients. Also, our analysis does not apply to procedures without the use of $\mathrm{CPB}$, because an important factor with influence on pharmacokinetic parameters is not used in these types of operations. In our opinion, off-pump cardiac surgery should be managed in a fashion similar to noncardiac surgery, where a repetition dose of the antibiotic is recommended after 2 to 3 half-lives of the substance used.

With regard to the pharmacokinetic analyses, the limited number of blood samples did not allow the use of a 2compartment model for pharmacokinetic modeling. Nevertheless, parameter estimation in our model is precise and observations and predictions are in good agreement over the whole concentration range, indicating no systemic deviations. Still, a more elaborate pharmacokinetic analysis (ie, calculations in a 2-compartment-model based on a larger and more heterogeneous cohort of patients) might further improve the accuracy of the predictions. Also, we did not include a control group of patients who received cefazolin in strict accordance with the STS guidelines both with regard to timing and dose ( $2 \mathrm{~g}$ vs $1 \mathrm{~g}$ ). A comparative analysis of drug levels might further elucidate these differences.

Our study does not differentiate between bound and unbound fractions of cefazolin. The free partition of drug that is not bound to plasma proteins is often considered to be the pharmacologically active portion. Unfortunately, 
the measurement of bound versus unbound cefazolin is technically demanding. The differential determination of drug partitions would offer further insight into the influence of perioperative changes in albumin levels and is an interesting field of future research.

There is a general debate about PAP for cardiac surgery with use of CPB. Both the duration and choice of antibiotic agent were examined in 2 meta-analyses. ${ }^{26,27}$ The results suggest beneficial effects of the extension of PAP to 24 hours and an escalation from a first- to a secondgeneration cephalosporin. Clinicians might consider changing their practice and discontinuing use of cefazolin. Still, the authors of the meta-analyses acknowledge a considerable heterogeneity of the included studies and call for prospective trials to confirm their suggestions. With regard to the microbiology results obtained from our patients, cefazolin covers $>90 \%$ of the pathogens found and is therefore well suited for perioperative antibiotic prophylaxis in our hospital. This situation will likely differ considerably in different regions with a higher prevalence of bacterial resistance. In these areas, cefazolin might not be appropriate for the prevention of SSI.

\section{CONCLUSIONS}

Two grams of cefazolin at the induction of anesthesia with a repeat dose of $2 \mathrm{~g}$ after the initiation of $\mathrm{CPB}$ appears to be a safe and simple dosing regimen that ensures adequate drug levels to target a majority of pathogens of SSIs. Pharmacokinetic modeling demonstrated a significant influence of CPB on both the volume of distribution and elimination of cefazolin. Other relevant influences of pharmacokinetic characteristics were levels of albumin and protein, as well as creatinine clearance.

\section{Conflicts of Interest Statement}

Authors have nothing to disclose with regard to commercial support.

\section{References}

1. Filsoufi F, Castillo JG, Rahmanian PB, Broumand SR, Silvay G, Carpentier A, et al. Epidemiology of deep sternal wound infection in cardiac surgery. J Cardiothorac Vasc Anesth. 2009;23:488-94.

2. Kubota H, Miyata H, Motomura N, Ono M, Takamoto S, Harii K, et al. Deep sternal wound infection after cardiac surgery. J Cardiothorac Surg. 2013;8:132.

3. Yavuz SS, Tarcin O, Ada S, Dincer F, Toraman S, Birbudak S, et al. Incidence, aetiology, and control of sternal surgical site infections. J Hosp Infect. 2013; $85: 206-12$.

4. Miyahara K, Matsuura A, Takemura H, Mizutani S, Saito S, Toyama M. Implementation of bundled interventions greatly decreases deep sternal wound infection following cardiovascular surgery. J Thorac Cardiovasc Surg. 2014;148: 2381-8.

5. Edwards FH, Engelman RM, Houck P, Shahian DM, Bridges CR. Society of Thoracic Surgeons. The Society of Thoracic Surgeons Practice Guideline Series: antibiotic prophylaxis in cardiac surgery, part I: duration. Ann Thorac Surg. 2006;81:397-404.

6. Engelman R, Shahian D, Shemin R, Guy TS, Bratzler D, Edwards F, et al. The Society of Thoracic Surgeons practice guideline series: antibiotic prophy- laxis in cardiac surgery, part II: antibiotic choice. Ann Thorac Surg. 2007;83: 1569-76.

7. Tamayo E, Gualis J, Florez S, Castrodeza J, Eiros Bouza JM, Alvarez FJ. Comparative study of single-dose and 24-hour multiple-dose antibiotic prophylaxis for cardiac surgery. J Thorac Cardiovasc Surg. 2008;136:1522-7.

8. Zanetti G, Giardina R, Platt R. Intraoperative redosing of cefazolin and risk for surgical site infection in cardiac surgery. Emerg Infect Dis. 2001;7:828-31.

9. Waltrip T, Lewis R, Young V, Farmer M, Clayton S, Myers S, et al. A pilot study to determine the feasibility of continuous cefazolin infusion. Surg Infect. 2002;3: 5-9.

10. Adembri C, Ristori R, Chelazzi C, Arrigucci S, Cassetta MI, De Gaudio AR, et al. Cefazolin bolus and continuous administration for elective cardiac surgery: improved pharmacokinetic and pharmacodynamic parameters. J Thorac Cardiovasc Surg. 2010;140:471-5.

11. Miller KW, McCoy HG, Chan KK, Fischer RP, Lindsay WG, Seifert RD, et al. Effect of cardiopulmonary bypass on cefazolin disposition. Clin Pharm Ther. 1980;27:550-6.

12. Lehot JJ, Reverdy ME, Etienne J, Corot C, Nervi C, Sear J, et al. Cefazolin and netilmicin serum levels during and after cardiac surgery with cardiopulmonary bypass. J Cardiothorac Anesth. 1990;4:204-9.

13. Fellinger EK, Leavitt BJ, Hebert JC. Serum levels of prophylactic cefazolin during cardiopulmonary bypass surgery. Ann Thorac Surg. 2002;74:1187-90.

14. Miglioli PA, Merlo F, Calabro GB, Allerberger F, Fille M. Cefazolin concentrations in serum during cardiopulmonary bypass surgery. Drugs Exper Clin Res. 2005;31:29-33.

15. Caffarelli AD, Holden JP, Baron EJ, Lemmens HJ, D'Souza H, Yau V, et al. Plasma cefazolin levels during cardiovascular surgery: effects of cardiopulmonary bypass and profound hypothermic circulatory arrest. J Thorac Cardiovasc Surg. 2006;131:1338-43.

16. Kosaka T, Hosokawa K, Shime N, Taniguchi F, Kokufu T, Hashimoto S, et al. Effects of renal function on the pharmacokinetics and pharmacodynamics of prophylactic cefazolin in cardiothoracic surgery. Eur J Clin Microbiol Infect Dis. 2012;31:193-9.

17. Akl BF, Richardson G. Serum cefazolin levels during cardiopulmonary bypass. Ann Thorac Surg. 1980;29:109-12.

18. Andreas M, Zeitlinger M, Hoeferl M, Jaeger W, Zimpfer D, Hiesmayr JM, et al. Internal mammary artery harvesting influences antibiotic penetration into presternal tissue. Ann Thorac Surg. 2013;95:1323-9; discussion 1329-30.

19. Hutschala D, Skhirtladze K, Kinstner C, Mayer-Helm B, Muller M, Wolner E, et al. In vivo microdialysis to measure antibiotic penetration into soft tissue during cardiac surgery. Ann Thorac Surg. 2007;84:1605-10.

20. Brill MJ, Houwink AP, Schmidt S, Van Dongen EP, Hazebroek EJ, van Ramshorst B, et al. Reduced subcutaneous tissue distribution of cefazolin in morbidly obese versus non-obese patients determined using clinical microdialysis. J Antimicrob Chemother. 2014;69:715-23.

21. Andreas M, Zeitlinger M, Wisser W, Jaeger W, Maier-Salamon A, Thalhammer F, et al. Cefazolin and linezolid penetration into sternal cancellous bone during coronary artery bypass grafting. Eur J Cardiothorac Surg. 2015;48:758-64.

22. Poeran J, Mazumdar M, Rasul R, Meyer J, Sacks HS, Koll BS, et al. Antibiotic prophylaxis and risk of Clostridium difficile infection after coronary artery bypass graft surgery. J Thorac Cardiovasc Surg. 2016;151:589-97.e2.

23. Zanetti G, Flanagan HL Jr, Cohn LH, Giardina R, Platt R. Improvement of intraoperative antibiotic prophylaxis in prolonged cardiac surgery by automated alerts in the operating room. Infect Control Hosp Epidemiol. 2003;24:13-6.

24. Nair BG, Newman SF, Peterson GN, Wu WY, Schwid HA. Feedback mechanisms including real-time electronic alerts to achieve near 100\% timely prophylactic antibiotic administration in surgical cases. Anesthes Analg. 2010;111: 1293-300.

25. Wildschut ED, Ahsman MJ, Allegaert K, Mathot RA, Tibboel D. Determinants of drug absorption in different ECMO circuits. Intensive Care Med. 2010;36: 2109-16.

26. Lador A, Nasir H, Mansur N, Sharoni E, Biderman P, Leibovici L, et al. Antibiotic prophylaxis in cardiac surgery: systematic review and meta-analysis. J Antimicrob Chemother. 2012;67:541-50.

27. Mertz D, Johnstone J, Loeb M. Does duration of perioperative antibiotic prophylaxis matter in cardiac surgery? A systematic review and meta-analysis. Ann Surg. 2011;254:48-54.

Key Words: cefazolin, pharmacokinetics, perioperative, NONMEN, perioperative prophylaxis 